OPEN ACCESS

University of Dundee

\title{
1-3 Piezocomposite design optimised for high frequency kerfless transducer arrays
}

Démoré, C.E.M.; Cochran, S.; Garcia-Gancedo, L.; Dauchy, F.; Button, T.W.; Bamber, J.C.

Published in:

Proceedings of the 2009 IEEE Ultrasonics Symposium

DOI:

10.1109/ULTSYM.2009.5442007

Publication date:

2009

Document Version

Early version, also known as pre-print

Link to publication in Discovery Research Portal

Citation for published version (APA):

Démoré, C. E. M., Cochran, S., Garcia-Gancedo, L., Dauchy, F., Button, T. W., \& Bamber, J. C. (2009). 1-3

Piezocomposite design optimised for high frequency kerfless transducer arrays. In Proceedings of the 2009

IEEE Ultrasonics Symposium IEEE Computer Society. https://doi.org/10.1109/ULTSYM.2009.5442007

\section{General rights}

Copyright and moral rights for the publications made accessible in Discovery Research Portal are retained by the authors and/or other copyright owners and it is a condition of accessing publications that users recognise and abide by the legal requirements associated with these rights.

- Users may download and print one copy of any publication from Discovery Research Portal for the purpose of private study or research.

- You may not further distribute the material or use it for any profit-making activity or commercial gain.

- You may freely distribute the URL identifying the publication in the public portal.

Take down policy

If you believe that this document breaches copyright please contact us providing details, and we will remove access to the work immediately and investigate your claim. 


\title{
1-3 Piezocomposite Design Optimised for High Frequency Kerfless Transducer Arrays
}

\author{
C.E.M. Démoré, S. Cochran \\ Institute for Medical Science and Technology \\ University of Dundee \\ Dundee, UK \\ cdemore@ieee.org
}

\author{
L. Garcia-Gancedo, F. Dauchy, T.W. Button \\ Functional Materials Group \\ University of Birmingham \\ Birmingham, UK
}

\author{
J.C. Bamber \\ Joint Department of Physics \\ Institute of Cancer Research and Royal Marsden NHS Trust \\ Sutton, Surrey, UK
}

\begin{abstract}
Piezocomposites that can operate at frequencies above $30 \mathrm{MHz}$ without spurious modes are required in order to develop sufficiently sensitive high frequency arrays for high resolution imaging. However, scaling down of conventional piezocomposite fabrication techniques becomes increasingly difficult as dimensions decrease with increasing frequency. The approach presented here is to use micro-moulded 1-3 piezocomposites and a distribution of piezoelectric segment size and separation. Innovative approaches to composite pattern design, based on a randomized spatial distribution, are presented. Micro-moulding techniques are shown to be suitable for fabricating composites with dimensions required for high frequency composites. Randomized piezocomposite patterns are modeled and are shown to suppress spurious modes.
\end{abstract}

Keywords-micromoulding; 1-3 composite, high-frequency array

\section{INTRODUCTION}

Transducer arrays operating at frequencies above $30 \mathrm{MHz}$ have been under investigation for some time because of their many potential biomedical imaging applications and improved image quality compared to the single element transducers presently in use. Very fine scale 1-3 piezocomposites are needed to take advantage of the improved acoustic impedance and electromechanical coupling coefficient compared to bulk ceramic while avoiding spurious modes. The development of such composites has been limited by the difficulty in fabricating kerfs with decreasing dimensions corresponding to increasing frequency. Laser machining of array elements [1], and dicing composites with triangular pillars [2] have been investigated to extend the frequency range for miniature arrays. However, the development of fine-scale piezocomposites has in general been limited by the geometrical restrictions of diceand-fill fabrication techniques. An alternative approach presented in this paper is to use micro-moulded piezocomposites. These 1-3 piezocomposites offer particular advantages because of the small dimensions possible $(<10 \mu \mathrm{m})$, and because the ceramic phase can be positioned within the polymer matrix wherever best suited for a particular device.
Micro-moulded piezocomposites, with shaped ceramic segments and epoxy filler, can be used as the substrate for kerfless arrays. A diagram of the envisaged array is shown in Fig. 1. Because kerfless array elements are defined by photolithographically patterned electrodes on the surface of the composite [3], rather than by physically separating the elements, it is possible to pattern electrodes with $15 \mu \mathrm{m}$ pitch, i.e. wavelength spacing for $100 \mathrm{MHz}$ linear arrays. The design of the composite must take into account the array element geometry to minimize unwanted modes and maximize performance. Finite element analysis (FEA) has been crucial in the design of composite patterns that suppress spurious modes and are also suitable for micro-moulding.

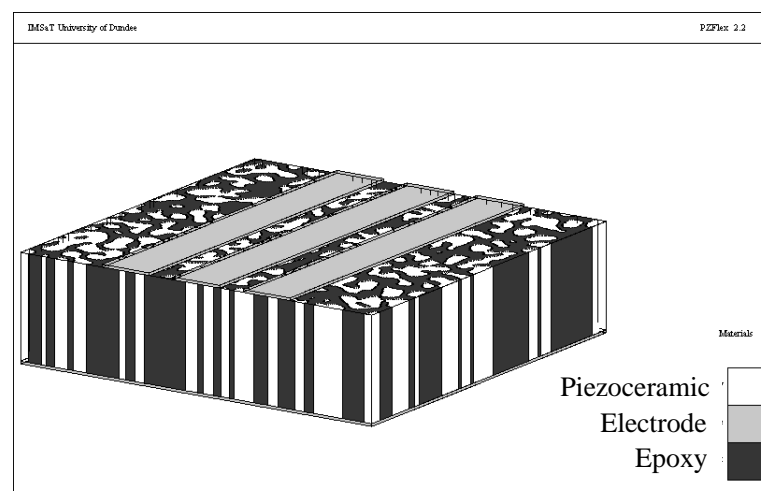

Figure 1. Diagram of kerfless array section with micro-moulded piezocomposite

In this paper we report advances in the development of fine-scale composites aimed at kerfless high frequency arrays with minimised interelement coupling for devices operating up to $100 \mathrm{MHz}$. Composite design techniques are presented in the next section followed by piezocomposite fabrication processes and evaluation of both fabricated and modeled composite designs.

The work reported here has been supported by the Engineering and Physical Research Council, UK. 


\section{PIEZOCOMPOSITE DESIGN AND FABRICATION}

\section{A. Piezocomposite Pattern}

One method for creating a 1-3 piezocomposite material suitable for high frequency arrays is to reduce the size of the ceramic pillars in a regular pattern of pillars. However, fabricating pillars of ceramic with very fine pillar dimensions becomes increasingly difficult as the pillar dimensions become smaller, and consequently spurious modes cannot be avoided. In addition, very tall thin pillars are prone to falling or standing askew. The approach taken here is to introduce a distribution of shapes and sizes of the ceramic segments and the width of the composite filler material surrounding the ceramic. Non-pillar shapes can improve the structural rigidity of the ceramic segments and be less prone to leaning or falling over. Moreover, by avoiding uniform or regular shapes of ceramic segments, any spurious modes within the composite will be spread over a broad enough frequency range to have negligible effect on the composite performance. The resonance in the thickness of the composite is the only coherent mode and therefore the composite can function well as a thickness mode transducer.

An algorithm has been developed in order to generate a randomized spatial pattern of ceramic within the composite and thus a distribution of the relevant sizes. The algorithm is based on a correlation length and is adapted from elsewhere [4]. In the spatial frequency domain, a modified Gaussian distribution $G(s)$ with a correlation length $a$ is combined with a random phase component $P(s)$, to give a randomized spatial frequency distribution $\Gamma$ :

$$
\begin{gathered}
G(s)=s^{2} e^{-\pi^{2} a^{2} s^{2}} \\
\Gamma(s)=G(s) \cos (P(s))+G(s) \sin (P(s))
\end{gathered}
$$

The real part of the inverse Fourier transform of $\Gamma$ is calculated to generate a spatial domain distribution, which is a continuous function. A threshold is applied to the distribution to obtain a binary pattern with a pre-determined volume fraction of ceramic to polymer. The correlation length $a$ in (1) indicates the nominal dimensions of the composite structure; a smaller correlation length will produce a pattern with smaller and more closely spaced ceramic features. The expected performance of the generated pattern can be evaluated with FEA. If the pattern is found to be suitable for a given application, it can then be used as a template to make a mould from which the composites will be made.

The benefit of using a randomized distribution to generate a pattern is that the nominal feature size can be controlled by the input correlation length, and the volume fraction of ceramic can be controlled by the threshold value. Moreover, small variations between the generated pattern and fabricated composites will not significantly affect its performance.

\section{B. Finite Element Analysis}

PZFlex (Weidlinger Associates Inc., Mountain View, CA, USA) has been used to create a 3-D model of the randomized composite patterns. The positions of the ceramic and epoxy within the composite are imported into the finite element (FE) model using the Import Material tool. The FE mesh size and the digitization of the composite pattern are both set to $1 \mu \mathrm{m}$, which corresponds to the mean grain sized used for fabricating the composites. Typical PZT-5H material properties are used for the ceramic phase and measured properties for Epofix (Struers, Solihull, UK), which has acoustic properties typical of piezocomposite filler materials [5].

A $300 \mu \mathrm{m}$ square section of randomized composite pattern was modeled to evaluate its performance. The thickness was set to $40 \mu \mathrm{m}$, corresponding to approximately $50 \mathrm{MHz}$ thickness mode operation. A continuous electrode was used on each face of the composite for initial evaluation, and the composites were acoustically unloaded. The electrical impedance was calculated.

\section{Piezocomposite Fabrication}

Net-shape ceramic processing techniques, such as viscous polymer processing, have been investigated as potential methods for fabricating ceramic structures with sufficiently small feature size. The fabrication process must also produce structures with high green strength prior to sintering in order to support structures with large height-to-width aspect ratio. A PZT-5H type ceramic (TRS610, TRS Technologies, State College, PA, USA) and Epofix have been used for composite fabrication.

Viscous polymer processing (VPP), in which high shear mixing is used to form a paste from ceramic powder, binders and solvent, has been developed to produce high density ceramic [6]. The ceramic paste is pressed into a mould and dried, ready for de-moulding and sintering. An improved VPP paste with reduced viscosity has facilitated the moulding of fine structures. The epoxy filler is cast into the spaces in the ceramic structures and the resulting structure is lapped to remove the ceramic stock (base) and excess epoxy. Electrodes are applied to the surfaces, and the composite is poled. Composites made with VPP techniques have been shown to have functional properties suitable for high frequency imaging [7].

\section{EVALUATION}

\section{A. Preliminary Composite Patterns}

Two composite patterns with simple shapes have been created to test the feasibility of moulding structures with small feature sizes and irregular shapes. The first pattern has ellipses with $70 \mu \mathrm{m}$ long axis and $15 \mu \mathrm{m}$ short axis, and approximately $30 \%$ volume fraction ceramic. The second pattern has $30 \mu \mathrm{m}$ radius arcs of $14 \mu \mathrm{m}$ width, and approximately $40 \%$ volume fraction ceramic. Composites with these patterns have been micro-moulded using VPP techniques. The ceramic structures in the VPP composites are initially approximately $100 \mu \mathrm{m}$ thick, and lapped to $40 \mu \mathrm{m}$ thick for testing. 
Fig. 2 shows micro-moulded green-state (before sintering) ceramic. Both the ellipse and arc accurately reproduce the form of the mould, including the taper in the height. The large height-to-width aspect ratios in both these shapes are possible due to the strength of the green-state ceramic. The arcs show that very fine structures can be formed and the irregular shape improves the structural rigidity of the ceramic bristle-block.
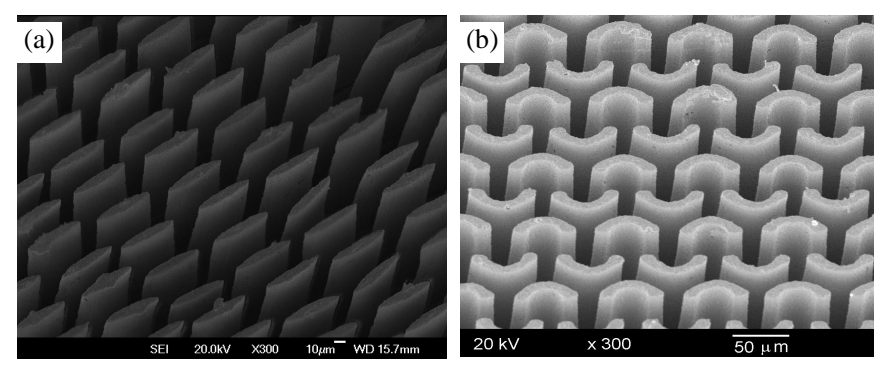

Figure 2. Green-state ceramic structures: (a) ellipses and (b) arcs.

Fig. 3 and Fig. 4 show microscope images of both sides of the ellipse and arc composites made with the VPP technique prior to electroding. Lateral features below $10 \mu \mathrm{m}$ and aspect ratios nearing 10 have been achieved with the composites, both in the ceramic structure and in the polymer matrix. The minimum separation of $4 \mu \mathrm{m}$ between ceramic structures and the minimum ceramic width of $8 \mu \mathrm{m}$ are of the order required for developing high frequency composites. In these two cases, the ceramic structure size was limited by the ability to create a mould of the desired shape. The tips of the ellipse indicate the minimum feature size that can be resolved with these net-shape processes if green-state strength is sufficient to support the structure.
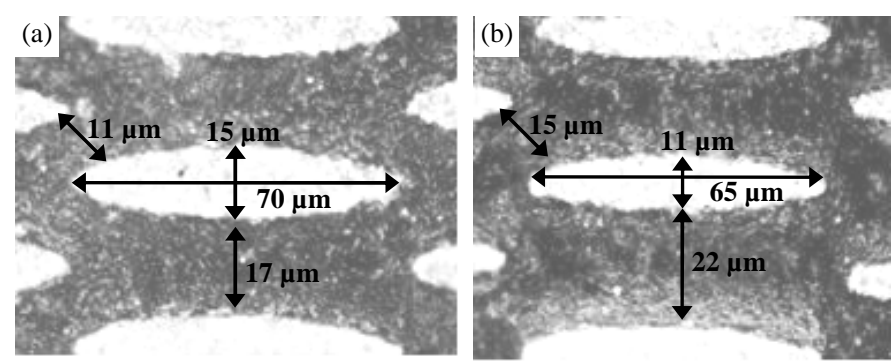

Figure 3. Ellipse shape composite pattern showing (a) stock end and (b) free end of micro-moulded ceramic structures. Light areas: ceramic, dark areas: epoxy.
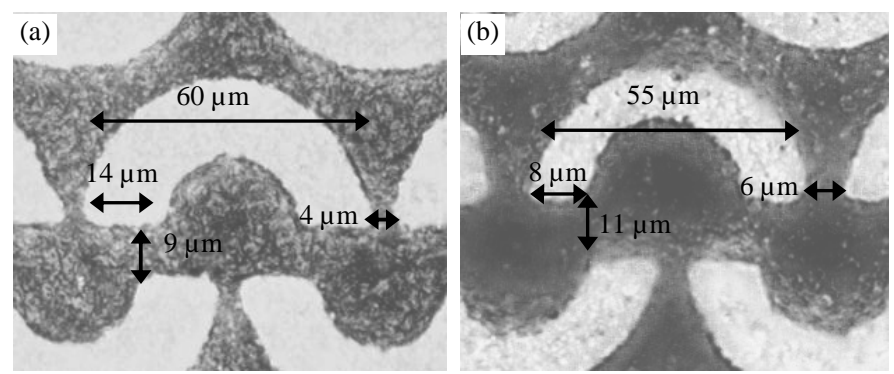

Figure 4. Arc shape composite pattern showing (a) stock end and (b) free end of micro-moulded ceramic structures Light areas: ceramic, dark areas: epoxy.
The ellipse composite of Fig. 3 was electroded and its electrical impedance response measured (4395A, Agilent Technologies UK Ltd., Wokingham, UK) and compared to FE calculation of the impedance for an ellipse. The FE model was of one quarter of the ellipse with symmetry conditions in all lateral directions and $40 \mu \mathrm{m}$ thickness. The experimental measurement and FE calculation of impedance are shown in Fig. 5. Although the measured impedance is highly damped, the frequencies of the vibration modes correspond to FEA calculation of vibration modes in the ellipse. The ellipses are not long enough to have a good aspect ratio in the long axis, and the two resonance modes at about $30 \mathrm{MHz}$ correspond to vibration modes along the length of the ellipse. The main thickness mode, at approximately $50 \mathrm{MHz}$, is found in both measured and calculated spectra. However, the limited aspect ratio for the long axis does introduce spurious modes that couple into the thickness mode.

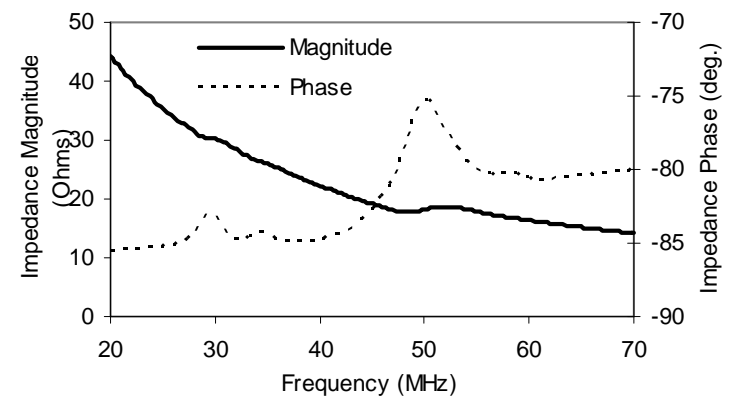

(a)

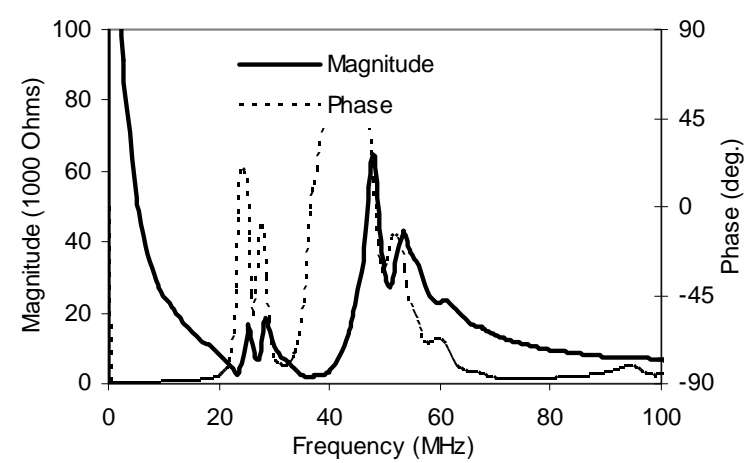

(b)

Figure 5. (a) Measured and (b) finite element model calculation of electrical impedance for ellipse composites.

\section{B. Randomised Composite Patterns}

A composite pattern generated with the process described above is shown in Fig. 6. A correlation length of $10 \mu \mathrm{m}$ was used for the spatial frequency distribution, and the threshold set to give $40 \%$ ceramic volume fraction. Correlation lengths on the order of $10 \mu \mathrm{m}$ were found to provide patterns with dimensions that are generally suitable for high frequency composite and that correspond with the dimensions feasible for fabrication by VPP. Although some of the smallest isolated features may not be easily reproduced in a fabricated composite, these are not likely to significantly affect the performance. 
This pattern was modeled with a thickness of $40 \mu \mathrm{m}$. The FE calculations of the electrical impedance spectra are shown in Fig. 7. There are no significant spurious modes even up to the frequency of the third harmonic, indicating that lateral modes have been spread over a broad frequency range. In addition, the electromechanical coupling coefficient $k_{T}$ is 0.68 , which is equal to the theoretical coupling coefficient for a composite with this volume fraction and materials [8].

Exactly the same composite pattern was modeled again, but with a thickness of $20 \mu \mathrm{m}$. The thickness mode resonance was found to be $95 \mathrm{MHz}$ and again, there were no significant spurious modes present. This demonstrates that the mean dimensions of the composite structure can be relatively large compared to the thickness while still providing a significant thickness mode response.

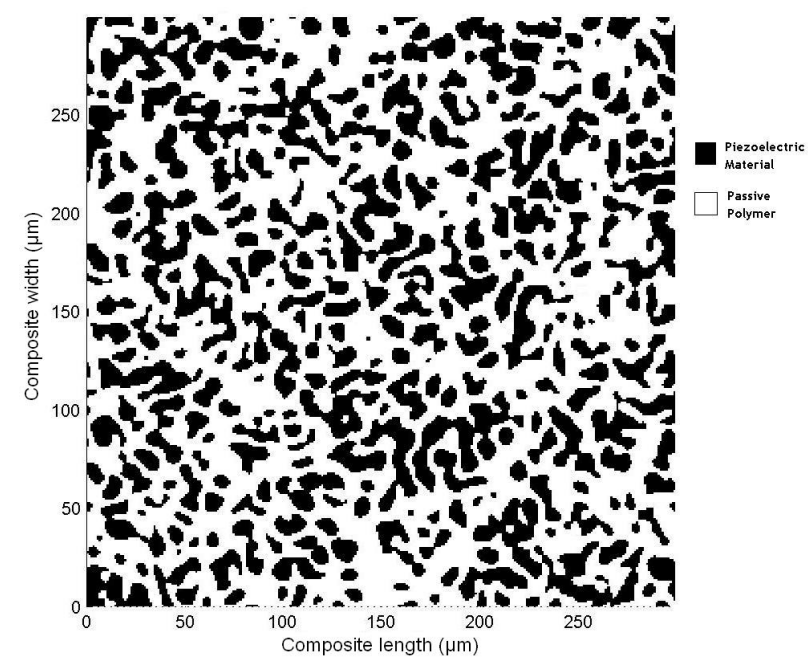

Figure 6. Randomised composite pattern.

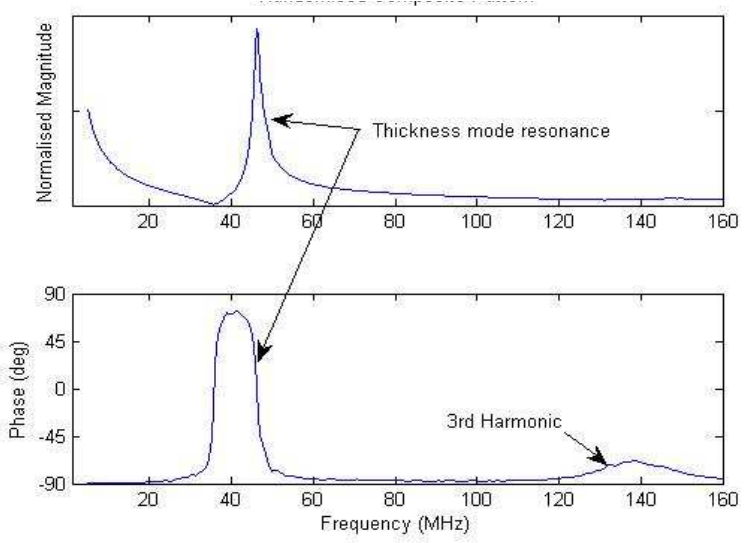

Figure 7. Calculated electrical impedance spectra for randomised composite pattern

\section{CONCLUSIONS}

Micro-moulding techniques such as viscous polymer processing have been shown to be suitable to fabricate unusual ceramic geometries for 1-3 piezocomposite material for high frequency kerfless transducer arrays. Composites with volume fractions above $40 \%$ and with a variety of geometries have been fabricated using mask-based micro-moulding. Ceramic structures with height-to-width aspect ratios of approximately 10 have been made with sufficient strength for de-moulding and sintering. The resonance modes of composites made with these moulded structures were found to correspond with the vibration modes expected from finite element analysis.

Innovative approaches for composite designs have been presented. An algorithm for generating ceramic patterns based on a randomized spatial frequency distribution was described. FEA of these randomized composite patterns has shown that spurious modes can be suppressed by using a distribution of ceramic geometries and dimensions. Thus the functional advantages of 1-3 piezocomposites can be gained, along with improved structural stability during fabrication, when device design is not limited by conventional fabrication techniques.

Structures with randomized distribution of piezoelectric segment size and pitch relax the restrictions imposed on a composite for fine-scale realisation whilst maintaining the performance and giving an effectively homogenous composite plate. This is of particular benefit for high-frequency transducers where the critical dimension is reduced.

\section{ACKNOWLEDMENT}

The authors thank Applied Functional Materials Ltd. for their assistance in this work.

\section{REFERENCES}

[1] M. Lukacs, Y. Jianlma, P. Guofeng, R. C. Garcia, E. Cherin, R Williams, J. Mehi, and F. S. Foster, "Performance and Characterization of New Micromachined High-Frequency Linear Arrays," IEEE Transactions on Ultrasonics, Ferroelectrics and Frequency Control, vol. 53, pp. 1719-1729, 2006.

[2] J. A. Brown, E. Cherin, J. Yin, and F. S. Foster, "Fabrication and Performance of a High-Frequency Geometrically Focussed Composite Transducer with Triangular Pillar Geometry," in Ultrasonics Symposium, 2007. IEEE, 2007, pp. 80-83.

[3] A. L. Bernassau, et al., "Surface Preparation of 1-3 Piezocomposite Material for Microfabrication of High Frequency Transducer Arrays," ," 2007 IEEE Ultrasonics Symposium, pp.96-99, 2007

[4] J. C. Bamber and R. J. Dickinson, "ULTRASONIC B-SCANNING - A COMPUTER-SIMULATION," Physics in Medicine and Biology, vol. 25, pp. 463-479, 1980.

[5] A. L. Bernassau, D. Hutson, C. E. M. Demore, S. Cochran, "Characterisation of an epoxy filler for piezocomposite material compatible with microfabrication processes," 2008 IEEE Ultrasonics Symposium, 2008, pp.62-65, 2008

[6] S. Cochran, A. Abrar, K. J. Kirk, Z. Dou, T. W. Button, S. Bo, and C. Meggs, "Net-shape ceramic processing as a route to ultrafine scale 1-3 connectivity piezoelectric ceramic-polymer composite transducers," Proceedings 2004 IEEE Ultrasonics Symposium, vol. 3, pp. 1682-1685, 2004.

[7] D. MacLennan, J. Elgoyhen, T. W. Button, C. E. M. Demore, H. Hughes, C. Meggs, S. Cochran, "Properties and Application-Oriented Performance of High Frequency Piezocomposite Ultrasonic Transducers," 2007 IEEE Ultrasonics Symposium, pp.100-103, 2007

[8] W. A. Smith and B. A. Auld, "Modeling 1-3 Composite Piezoelectrics Thickness-Mode Oscillations," IEEE Transactions on Ultrasonics Ferroelectrics and Frequency Control, vol. 38, pp. 40-47, Jan 1991.WA Smith effective properties. 